\title{
An audit and investigation into the influence of social media on weaning practices
}

\author{
S. O'Keeffe ${ }^{1}$, A. Mezynska ${ }^{2}$, K. O'Connor ${ }^{3}$, M. Redmond ${ }^{3}$ and J.L. O'Neill ${ }^{3}$ \\ ${ }^{1}$ Student of Public Health Nutrition (BSc), School of Biological Health Sciences, Technological University Dublin, \\ Kevin Street, Dublin, \\ ${ }^{2}$ Student of Human Nutrition (BSc), School of Agriculture, Food Science and Veterinary Medicine, Belfield, Dublin 4 \\ and \\ ${ }^{3}$ Danone Nutricia, Block 1, Deansgrange Business Park, Deansgrange, Dublin
}

The correct introduction of solid foods is important for the health of the infant to ensure the child is developmentally and physiologically able to consume the foods and to avoid nutrient deficiencies ${ }^{(1)}$. The World Health Organisation recommends the optimal diet is the introduction of solid foods from 6 months onwards in addition to breastmilk, or infant formula where breastfeeding is not available $^{(2)}$. Complementary foods should be appropriate in quantity, timing, texture, variety and suited to the individual child ${ }^{(2)}$. Social media can be influential because it is ubiquitous, widely used, entertaining and engaging ${ }^{(3)}$. The aim of this study was to investigate the influence of social media on weaning practices.

Two focus group sessions were conducted ( $\mathrm{n}=9$ and 10 participants, respectively). Participants were recruited from the South Dublin/ Wicklow area through posts on Facebook and fliers in local businesses. A social media audit was conducted over a 4-day period including one weekend day and included Instagram, blogs and YouTube. Social listening was completed through the Linkfluence software for a period of 6 months. A sample of parents with a child aged 4-10 months $(n=513)$ completed a 29-item questionnaire online. Analysis included chi-square and descriptive statistics to calculate percentages conducted through to SPSS ${ }^{\circledR}$ for Windows ${ }^{\mathrm{TM}}$ version 26 (SPSS Inc, Chicago, IL).

Globally over a 6-month period there were $72,382,899$ online posts related to infant weaning. The main sources were Twitter (49\%), blogs $(19 \%)$, Facebook (13\%), Instagram $(6 \%)$, forums $(5 \%)$ and websites $(5 \%)$. The focus group identified mothers as the primary decision maker regarding weaning, and their weaning decisions can be influenced by social media, excluding the timing of first introducing solid foods. It is reported that mothers were influenced by a wide range of people including micro-influencers. These influencers are people with expertise, are authentic and honest, discuss a wide variety of topics and who appeal to their personal preferences. The influence of social media was perceived as positive by $54 \%$ of questionnaire respondents. Common topics discussed on social media from the focus group and social media audit include recipes, daily meal plans and advice for weaning.

This study found social media to have an influence on weaning practices in general, but did not appear to influence the timing of starting complementary feeding. Just over half of participants perceived social media to positively influence complementary feeding practices. As social media may influence weaning decisions, qualified professionals could utilise these platforms to disseminate accurate information to optimise the health of the infant. Further research is needed on the influence of social media on weaning practices.

1. Castemiller J, de Henauw S, Hirsch-Ernst K-I et al. (2019) EFSA Journal 17, 9, 5780, 241

2. World Health Organisation (2020) [Available at: https://www.who.int/nutrition/topics/complementary_feeding/en/] (Accessed January 2020)

3. Social Magnets (2020) [Available at: https://www.socialmagnets.net/how-social-media-influences-people/] (Accessed March 2020) 